\title{
Preconception care received by women attending antenatal clinics at a Teaching Hospital in Southern Sri Lanka
}

\author{
Patabendige $\mathbf{M}^{1}$, Goonewardene I $\mathbf{M ~ R}^{2}$
}

\section{Abstract \\ Introduction: Preconception Care (PCC) is an important component of reproductive health care.}

Objectives: To study the level of preconception preparedness of pregnant women, and factors influencing it, in order to identify possible strategies to improve PCC.

Design and Setting: A descriptive cross-sectional study conducted from 10th July to 13th August 2012 in the Antenatal Clinics of the Academic Obstetrics and Gynaecology Unit at Teaching Hospital, Mahamodara, Galle.

Method: A consecutively recruited, convenient sample of 250 pregnant women presenting for booking at $<28$ weeks gestation was studied. Data on demographic characteristics, PCC received and responses to 18 questions on preconception health knowledge were collected using an interviewer-administered, pre-tested structured questionnaire. Responses for each question were scored out of 10 and correlated with the demographic data of the subjects.

Results: The mean age of the subjects was 27.8 years (95\% Cl 27.0-28.6) and 124 $(49.6 \%)$ were primigravidae. Only $68(27.2 \%)$ of subjects had received PCC and 95 $(38 \%)$ had unplanned pregnancies. Age $<26$ yrs, monthly family income of $<$ Rs. 15,000 , educational level < General Certificate of Education, Ordinary Level (G.C.E.O/L) and unemployment carried almost a doubling of the risk of unplanned pregnancies. (RRs 1.7 $-2.4,95 \%$ Cls $1.2-3.9, p<0.005$ ). An educational level < G.C.E.O/L also carried a higher risk of not receiving PCC (RR 1.4, 95\% Cl 1.2-1.6, $\mathrm{p}<0.0001)$. Knowledge of the value of early registration with a Public Health Midwife (PHM) and preconceptional Rubella vaccination, and the risks associated with increased age, consanguinity, and exposure to passive smoking were satisfactory. Knowledge regarding pregnancy planning, awareness of PCC, effects of pre-pregnancy weight on fertility, folic acid supplementation, fertile period and birth spacing were unsatisfactory. The leading sources of preconceptional health knowledge were PHM (16.8\%), specialist obstetrician (8.4\%) and media (7.6\%).

Conclusion: PCC of women is suboptimal and needs more attention. The primary health care team, general practitioners and specialist obstetricians should be motivated and trained to provide preconception health education and PCC to late adolescents and young women in Southern Sri Lanka.

Key words: Preconception care, preconception health education, Southern Sri Lanka

\section{Introduction}

Preconception care (PCC) has been recognized as an important com-

\footnotetext{
${ }^{1}$ Demonstrator, Department of Physiology,

2 Senior Professor and Head, Department of Obstetrics and Gynaecology, Faculty of Medicine, University of Ruhuna, Galle, Sri Lanka.

Correspondence: M Patabendige

E-mail: mpatabendige@gmail.com

Competing interests: None.
}

ponent of reproductive health care in women ${ }^{1}$. PCC provides a good foundation for the well-being of both mother and baby through a successful pregnancy and to a healthier future generation in a country. Sri Lanka does not have a well organized program of PCC other than prenatal supplementation with folic acid and Rubella vaccination.

PCC can be defined as a set of interventions which aim to identify and modify biomedical, behavioral and social risks to a woman's health or pregnancy outcome through prevention and management ${ }^{2}$. The main goals are to improve birth outcomes in future pregnancies through health education, risk assessment and appropriate interventions wherever needed ${ }^{3}$. PCC reduces potential risk factors which may adversely affect future pregnancies, and becomes even more important especially when there is a pre-existing maternal medical illness threatening the mother or the outcome of pregnancy. In the United States of America (USA), up to more than $50 \%$ of pregnancies have been reported to be unplanned and unintended ${ }^{4}$. An unmet need for family planning of $8.4 \%$ and a teenage pregnancy rate of $6.5 \%$ has been reported in Sri Lanka in $2009^{5}$. It has been shown that unintended, unwanted or mistimed pregnancies are associated with a significantly higher risk of low birth weight and preterm delivery ${ }^{6}$. Furthermore, there is a possible relationship between low birth weight and increased susceptibility to chronic diseases in later life ${ }^{7}$. Increased rate of teenage pregnancies is also another burden to reproductive healthcare.

There is insufficient evidence regarding many PCC interventions and the best methods of integrating them into primary health care (PHC) ${ }^{8}$. Based on current best available evidence, women of childbearing age planning a pregnancy should take $0.04 \mathrm{mg}$ folic acid daily, commencing at least one month before conception and continuing it throughout the first trimester of pregnancy. The dose of folic acid is recommended to be increased to $5 \mathrm{mg}$ daily in women with obesity, epilepsy, diabetes mellitus, malabsorption syndromes or a previous history of a fetus affected by a neural tube defect ${ }^{9,10}$. Although there are concerns and conflicting reports of the possibility of an increased risk of colorectal cancer with increased 
intake of folic acid, routine prenatal supplementation with folic acid is recommended. Consumption of folate as natural food folate has been shown to be ineffective in optimizing the folate status because of its lower bioavailability. Therefore supplemental folate is required and many countries have commenced food fortification with folate ${ }^{10}$. It has been reported that PCC improves folate intake ${ }^{11}$. However folic acid supplementation programs and folic acid fortification programs should be carefully monitored until the concerns regarding the possible increased risk of colo-rectal cancer is resolved $^{12}$. Although Sri Lanka has a program of prenatal supplementation with folic acid for women planning a pregnancy, national data for the population coverage of this program is not available ${ }^{13}$.

It has been recommended that National Rubella Vaccination Programs should ensure that their strategies should include protection of women in childbearing age, in order to prevent Congenital Rubella Syndrome ${ }^{14}$. In 2009, 94.8\% of pregnant women in Sri Lanka were protected against Rubella at the time of antenatal registration ${ }^{5}$.

Two studies done in Colombo in 2003 and 2007 reported poor levels of $\mathrm{PCC}^{15,16}$. An external review of maternal and newborn health (MNH) in Sri Lanka in 2007 recommended that programs should be developed to address preconception needs and concerns especially among young people, in order to improve $\mathrm{MNH}$ outcomes ${ }^{16}$. In the National Strategic Plan on MNH for the period 20122016, a PCC package has been designed for implementation, indicators to monitor PCC have been defined, and targets have been set for $2016^{13}$. Therefore it was decided to study the current level of preconception preparedness and factors influencing it, among women attending antenatal clinics at a Teaching Hospital in Southern Sri Lanka. This would be of great value in implementing the PCC package and monitoring its coverage and impact in the population.

\section{Method}

A descriptive cross-sectional study was conducted from 10th July to 13th August 2012. From the pregnant women presenting for booking at the antenatal clinics of the Academic Department of Obstetrics and Gynaecology at Teaching Hospital, Mahamodara, Galle, a convenient sample of 250 consecutive pregnant women with less than 28 weeks of period of gestation (POG) were recruited. Data were collected by two trained interviewers using a pre-tested, structured questionnaire, after obtaining informed written consent. The questionnaire was administered in Sinhala and it consisted of two sections. Section- 01 was on socio-demographic details such as age, employment status, monthly family income and educational level. The parity, current POG at booking and the POG at which they registered with the Public Health Midwife (PHM) were also recorded. In section02 , there were 18 structured questions to evaluate the preconception health knowledge. These questions covered the main areas of PCC viz: pregnancy planning, knowledge on risks of consanguinity, familial inheritance, teratogenicity, importance of early registration with the $\mathrm{PHM}$, fertile period, effects of maternal age at conception, effect of pre-pregnancy weight on fertility, birth spacing, folic acid supplementation and vaccination against rubella.

Seven questions had yes or no responses and 11 had more than two responses with only one being correct. Each yes or correct response scored 10 and any other response scored zero giving a maximum possible score of 180. The frequency and percentage of correct responses and the scores for each correct response were calculated. Descriptive statistics were used to summarize the data. Pearson Chisquare test and Fisher's Exact test were performed for significance testing among categorical variables, and relative risks were calculated. A p value $<0.05$ was considered as statistically significant. Ethical approval was obtained from the Ethical Review Committee, Faculty of Medicine,
University of Ruhuna, Galle. Approval was also obtained from the Director, Teaching Hospital, Mahamodara.

\section{Results}

The mean age of women in the study sample was 27.8 years (95\% CI 27.028.6) with a range of 17 to 43 years. The median parity was 2 (IQR 1-2) with a range of 1 to 7 . Of the 250 subjects, $63(25.2 \%)$ had a monthly family income of less than Rs.15,000. A vast majority $(79.6 \%)$ of the women were housewives and $89(35.6 \%)$ of them had an educational level below the General Certificate of Education, Ordinary Level (G.C.E O/L). Of the 250 subjects, only $68(27.2 \%)$ had received PCC and 95 (38\%) had unplanned pregnancies (Table 1).

The mean preconception health knowledge score in the study sample was $108.7 / 180(60.4 \%$, 95\% CI $58 \%$ $63 \%)$. University graduates had the highest mean score of 140.2/180 (77.9\%, 95\% CI 72.6\% - 83.2) and those with an educational level of < grade 05 had the lowest mean score of $50.4 / 180$ (28\%, 95\% CI $20.4 \%$ $35.6 \%)$. Knowledge regarding rubella vaccination and the adverse effects to the baby by exposure to passive smoking in early pregnancy had very high scores of $98.8 \%$ and $97.2 \%$ respectively. Knowledge regarding the availability of PCC prior to embarking on a pregnancy had the lowest score of $27.2 \%$ [Table 1].

Knowledge of the value of early registration with a PHM and preconceptional rubella vaccination, and the risks associated with increased age, consanguinity, and exposure to passive smoking were satisfactory with scores above $75 \%$ in each. Knowledge regarding pregnancy planning, awareness of PCC, effects of pre-pregnancy weight on fertility, folic acid supplementation, fertile period and birth spacing were unsatisfactory. Although knowledge about folic acid scored $90.8 \%$, knowledge about adverse effects associated with not taking folic acid preconceptionally scored $61.2 \%$ and only $43.6 \%$ of women had received folic acid pre conceptionally (Table 1 ). 
Table 1. Unplanned pregnancies, preconception care received and preconception health knowledge score in relation to demographic characteristics, $(n=250)$

\begin{tabular}{|c|c|c|c|c|}
\hline & & $\begin{array}{c}\text { Unplanned pregnancies } \\
95(38 \%)\end{array}$ & $\begin{array}{l}\text { Preconception care } \\
\text { received } 68 \text { (27.2\%) }\end{array}$ & $\begin{array}{l}\text { Preconception health } \\
\text { knowledge score (\%) }\end{array}$ \\
\hline \multicolumn{5}{|l|}{ Age (years) } \\
\hline$<20$ & $(n=27)$ & $14(51.9)$ & $04(14.8)$ & 47.7 \\
\hline $20-25$ & $(n=49)$ & $28(57.1)$ & $12(24.5)$ & 53.6 \\
\hline $26-30$ & $(n=79)$ & $25(31.6)$ & $19(24.1)$ & 63.4 \\
\hline $31-35$ & $(n=59)$ & $16(27.1)$ & $20(33.9)$ & 65.8 \\
\hline$>35$ & $(n=36)$ & $12(33.3)$ & $13(36.1)$ & 63.9 \\
\hline \multicolumn{5}{|l|}{ Monthly family income } \\
\hline$<$ Rs. 15,000 & $(n=63)$ & $34(54)$ & $11(17.5)$ & 54.2 \\
\hline Rs. $15,000-25,000$ & $(n=122)$ & $45(36.9)$ & $34(27.9)$ & 59.5 \\
\hline$>$ Rs. 25,000 & $(n=65)$ & $16(24.6)$ & $23(35.4)$ & 68.1 \\
\hline \multicolumn{5}{|l|}{ Employment status } \\
\hline Employed & $(n=51)$ & $10(19.6)$ & $19(37.3)$ & 69.3 \\
\hline Unemployed & $(n=199)$ & $85(42.7)$ & $49(24.6)$ & 58.1 \\
\hline \multicolumn{5}{|l|}{ Educational level } \\
\hline$<$ Grade 05 & $(n=05)$ & $05(100)$ & 0 & 28.0 \\
\hline Grade 05 to Grade - 11 & $(n=84)$ & $49(58.3)$ & $10(11.9)$ & 50.9 \\
\hline G.C.E. Ordinary Level passed & $(n=76)$ & $22(28.9)$ & $24(31.6)$ & 60.9 \\
\hline G.C.E. Advanced Level passed & $(n=63)$ & $16(25.4)$ & $20(31.7)$ & 69.0 \\
\hline University graduates & $(n=22)$ & $3(13.6)$ & $14(63.6)$ & 77.9 \\
\hline \multicolumn{5}{|l|}{ Parity } \\
\hline Primipara & $(n=124)$ & $44(35.5)$ & $38(30.7)$ & 60.4 \\
\hline Multipara & $(n=118)$ & $45(38.1)$ & $29(24.6)$ & 61.5 \\
\hline Grandmultipara & $(n=08)$ & $06(75.0)$ & $01(12.5)$ & 43.3 \\
\hline
\end{tabular}

* G.C.E. $=$ General Certificate of Education

Table 2. Association of unplanned pregnancies and not receiving preconception care with demographic characteristics

\begin{tabular}{lcc}
\hline Demographic characteristic & Unplanned pregnancies & Not receiving preconception care \\
\hline Age $<26$ years & $\mathrm{RR}=1.8$ & $\mathrm{RR}=1.1$ \\
& $95 \% \mathrm{Cl}=1.3-2.5$ & $95 \% \mathrm{Cl}=1.0-1.3$ \\
& $\mathrm{p}=0.0002$ & $\mathrm{p}=0.15$ \\
Monthly family income < Rs.15,000 & $\mathrm{RR}=1.7$ & $\mathrm{RR}=1.2$ \\
& $95 \% \mathrm{Cl}=1.2-2.3$ & $95 \% \mathrm{Cl}=1.0-1.4$ \\
Educational level < G.C.E. O/L & $\mathrm{p}=0.0025$ & $\mathrm{p}=0.045$ \\
& $\mathrm{RR}=2.4$ & $\mathrm{RR}=1.4$ \\
Unemployment & $95 \% \mathrm{Cl}=1.7-3.3$ & $95 \% \mathrm{Cl}=1.2-1.6$ \\
& $\mathrm{p}<0.0001$ & $\mathrm{p}<0.0001$ \\
Multiparity & $\mathrm{RR}=2.2$ & $\mathrm{RR}=1.2$ \\
& $95 \% \mathrm{Cl}=1.2-3.9$ & $95 \% \mathrm{Cl}=1.0-1.5$ \\
& $\mathrm{p}=0.002$ & $\mathrm{p}=0.07$ \\
& $\mathrm{RR}=1.1$ & $\mathrm{RR}=1.1$
\end{tabular}

$\mathrm{RR}=$ Relative Risk. $\quad 95 \% \mathrm{Cl}=95 \%$ Confidence Interval. $\quad$ G.C.E. O/L = General Certificate of Education Ordinary Level. 
Risk factors for unplanned pregnancies included age $<26$ yrs, monthly family income of $<$ Rs. 15,000, educational level < G.C.E.O/L and unemployment, and they carried almost a doubling of the risk of unplanned pregnancies. (Relative Risks ranging from 1.7 - 2.4, 95\% Confidence Intervals ranging from $1.2-3.9, p<0.005)$. An educational level <G.C.E.O/L also carried a higher risk of not receiving PCC (RR 1.4, 95\% CI 1.2 - 1.6, p < 0.0001).

Of the 250 subjects, $192(76.8 \%)$ and $208(83.2 \%)$ were aware of the possible risks associated with a consan-guinous marriage and the possibility of inheriting diseases respectively. More than $90 \%$ of subjects were aware about folic acid and the importance of registering with a PHM early. However, only 153 (61.2\%) were aware about the possible adverse effects of not taking preconceptional folate and only 109 (43.6\%) had taken preconceptional folate. Although more than $98 \%$ were aware about rubella vaccination, only 239 (95.6\%) had received rubella vaccination and only 219 (87.6\%) were aware about the possible adverse effects of not having rubella vaccination. There were 140 (56\%) who were not aware about the fertile period and 201 (80.4\%) were aware about the adverse effects of increasing maternal age on fertility. However only, 127 (50.8\%) were aware that pre-pregnancy weight has an effect on fertility. There were 243 $(97.2 \%)$ who were aware about the possible adverse effects of passive smoking and 184 (73.6\%) who were aware about the possible adverse effects of irradiation. Of the 250 subjects, $189(75.6 \%)$ thought that the ideal spacing between two children should be 2 to 3 years, but 45 (18\%) did not have any idea about birth spacing.

The PHM was the commonest source of pre conception health education and she was responsible for providing PCC in $42(61.8 \%)$ of the 68 subjects who received PCC. Specialist obstetricians were responsible for providing PCC in $21(30.9 \%)$ of the 68 who received PCC. The media contributed to preconception health education in $19(27.9 \%)$ of the 68 who received PCC and $7.6 \%$ of the total study sample of 250 (Table 3).
Table 3. Sources of preconception health knowledge $(n=250)$

Source of preconception Number (\%) health knowledge

$\begin{array}{lr}\text { Public Health Midwife (PHM) } & 42(16.8 \%) \\ \text { Specialist obstetrician } & 21(8.4 \%) \\ \text { Media } & 19(7.6 \%) \\ \text { General practitioner } & 17(6.8 \%) \\ \text { Medical officer of health (MOH) } & 9(3.6 \%) \\ \text { Peers } & 5(2 \%) \\ \text { Total } & 68^{\star}(27.2 \%)\end{array}$

*Some women had received preconception health knowledge from multiple sources.

Women with planned pregnancies $(n=155)$ and women receiving PCC $(n=68)$ were more likely to register with the PHM early. ie. at $<8$ weeks. (RR 1.4, 95\% CI 1.2-1.7, p <0.001 and RR 1.3, 95\% CI 1.1.-1.5, p < 0.005 respectively). However no such association was seen with booking at Teaching Hospital Mahamodara early. ie < 20 weeks (Table 4).

Table 4. Association of unplanned pregnancies and preconception care with health seeking behavior

\begin{tabular}{|c|c|c|}
\hline & $\begin{array}{l}\text { Registration with the public } \\
\text { health midwife } \leq 8 \text { weeks }\end{array}$ & $\begin{array}{c}\text { Booking at Teaching Hospital, Mahamodara } \\
\text { at a period of gestation }<20 \text { weeks }\end{array}$ \\
\hline Unplanned pregnancies $(n=95)$ & $\begin{array}{c}54(57 \%) \\
\mathrm{RR}=0.7 \\
95 \% \mathrm{Cl}=0.6-0.9 \\
p<0.0001\end{array}$ & $\begin{array}{c}60(63.2 \%) \\
\mathrm{RR}=1.0 \\
95 \% \mathrm{Cl}=0.8-1.2 \\
p=0.92\end{array}$ \\
\hline Planned pregnancies $(n=155)$ & $\begin{array}{c}126(81 \%) \\
\mathrm{RR}=1.4 \\
95 \% \mathrm{Cl}=1.2-1.7 \\
\mathrm{p}<0.0001\end{array}$ & $\begin{array}{c}97(62.6 \%) \\
\mathrm{RR}=1.09 \\
5 \% \mathrm{Cl}=0.8-1.2 \\
p=0.92\end{array}$ \\
\hline Not receiving preconception care $(n=182)$ & $\begin{array}{c}122(67 \%) \\
R R=0.8 \\
95 \% \mathrm{Cl}=0.7-0.9 \\
p=0.004\end{array}$ & $\begin{array}{c}118(64.8 \%) \\
1 \mathrm{RR}=1.1 \\
95 \% \mathrm{Cl}=0.9-1.4 \\
p=0.28\end{array}$ \\
\hline Receiving preconception care $(n=68)$ & $\begin{array}{c}58(85.3 \%) \\
\mathrm{RR}=1.3 \\
95 \% \mathrm{Cl}=1.1-1.5 \\
p=0.004\end{array}$ & $\begin{array}{c}39(57.4 \%) \\
\mathrm{RR}=0.9 \\
95 \% \mathrm{Cl}=0.7-1.1 \\
p=0.28\end{array}$ \\
\hline
\end{tabular}

RR = Relative Risk. $95 \% \mathrm{Cl}=95 \%$ Confidence Interval. 


\section{Discussion}

The most important observations in the current study are that a relatively younger age, a lower level of education, unemployment, and a lower monthly family income, carried almost a doubling of the risk of unplanned pregnancies, and that a lower monthly family income also carried a higher risk of not receiving PCC. Therefore interventions to improve PCC should target this vulnerable population which reflects a vicious circle. The other important observation was that planned pregnancies and women receiving PCC were more likely to register with a PHM early, ie at $\leq 8$ weeks gestation. This would enable early detection of any risk factors in the pregnancy, appropriate remedial measures to be adopted if possible, and appropriate and early referral for specialist care when indicated.

In the current study there were $38 \%$ unplanned pregnancies and 10.8\% teenage pregnancies. In a study carried out in the same unit in 2005, a teenage pregnancy rate of $5.3 \%$ was reported. It was also found that teenage pregnancies were significantly associated with poor education, poverty, anaemia, pregnancy induced hypertension and preterm delivery. Most of these teenage pregnancies were unplanned and due to poor knowledge of contraception, and they could have been prevented by proper counseling ${ }^{18}$. Some women with unplanned and teenage pregnancies may not seek antenatal care until late in the pregnancy. Therefore, there is a possibility of some of them being not included in the current study.

A considerable proportion of late adolescents in the Southern Province have been shown to be sexually active $^{19,20}$. Considering the probable increasing trend in the rates of teenage pregnancy in the region, and the younger age associated with unsatisfactory PCC, a concerted effort is required to improve sexual and reproductive health knowledge in adolescents and young adults.

In the current study, although more than $90 \%$ of subjects were aware about folic acid and the importance of registering with a PHM early but only $61.2 \%$ were aware about the possible adverse effects of not taking preconceptional folic acid and only $43.6 \%$ had taken preconceptional folic acid. In the USA, folate intake was reported to be approximately $34 \%$ among women in reproductive age despite awareness programs $^{21}$.

In the current study, rubella vaccination was quite satisfactory with $95.6 \%$ having received it. This coverage is comparable with the national average and probably reflects the successful implementation of the National Rubella Vaccination Programme in Southern Sri Lanka. In the National Strategic Plan for Sri Lanka, the target for 2016 is to have at least $98 \%$ of pregnant women protected against rubella at the time of antenatal registration ${ }^{13}$. In the current study the knowledge on fertile period, birth spacing and common familial diseases were suboptimal.

Although a non-probability sample was used, the data from the current study probably reflects to a significant degree the situation in the general population in the Galle district in particular and perhaps Southern Sri Lanka in general. This is because approximately $85 \%$ of deliveries in Sri Lanka occur in tertiary care facilities ${ }^{22}$. The demographic characteristics of the study population probably reflect the general population in the Galle district.

In the current study only $27.2 \%$ of women had received PCC. A study done in Colombo in 2001 reported that only $21 \%$ of women had received PCC

at that time ${ }^{15}$. The current study, carried out almost 10 years later, indicates that despite improvements in the primary health care system, PCC has not been properly addressed still in Southern Sri Lanka.

Overall a markedly greater proportion of women in Colombo had acquired some degree of preconception health knowledge in comparison to women in Galle. Although electronic and print media were the main sources and contributed to approximately $82 \%$ of preconception health knowledge among women attending antenatal clinics in Colombo $^{15}$, and $60.2 \%$ of women in an antenatal ward reported receiving preconception health knowledge from telecasted maternal health education programs ${ }^{16}$, only $7.6 \%$ of women in Galle had gained preconception health knowledge from the media. This is probably due to socio-economic and demographic differences in the two populations. The proportion of women $<24$ yrs was possibly less in the Colombo study compared to the Galle study $(20 \%$ vs $27 \%, p<0.07)$ and the proportion of women educated to a level < G.C.E. O/L was markedly less in the Colombo study compared to the Galle study $(18 \%$ vs $36 \%$, p < 0.0001) (Table 6). Furthermore, although this aspect was not analyzed in the Colombo study, $25 \%$ of women in the Galle study had a monthly family income of < Rs. 15,000/=. Apparently the relatively young, poor and less educated women in the Galle district are not keen to read or watch health education material in the print or electronic media.

Table 5. Sources of preconception health knowledge, Colombo ${ }^{15}$ vs Galle

\begin{tabular}{lccc}
\hline $\begin{array}{l}\text { Source of preconception } \\
\text { health knowledge }\end{array}$ & $\begin{array}{c}\text { Colombo [15] } \\
(n=225)\end{array}$ & $\begin{array}{c}\text { Galle } \\
(n-250)\end{array}$ & $p$ \\
\hline Media (Electronic and print) & $184(81.8 \%)$ & $19(7.6 \%)$ & $<0.0001$ \\
Public Health Midwife & $113(50.2 \%)$ & $42(16.8 \%)$ & $<0.0001$ \\
Doctors & $81(36.0 \%)$ & $47(18.8 \%)$ & $<0.0001$ \\
Peers & $78(34.7 \%)$ & $5(2 \%)$ & $<0.0001$ \\
\hline
\end{tabular}


Table 6. Socio-demographic characteristics, Colombo ${ }^{15}$ vs Galle

\begin{tabular}{lccc}
\hline $\begin{array}{l}\text { Source-demographic } \\
\text { characteristic }\end{array}$ & $\begin{array}{c}\text { Colombo } \\
(n=225)\end{array}$ & $\begin{array}{c}\text { Galle } \\
(n-250)\end{array}$ & $p$ \\
\hline Age < 24yrs & $45(20 \%)$ & $68(27 \%)$ & $=0.07$ \\
Educational level < G.C.E. O/L & $41(18 \%)$ & $89(36 \%)$ & $<0.0001$ \\
\hline
\end{tabular}

Approximately $35 \%$ of women in Colombo had gained some knowledge of preconception health from their peers, in contrast to only $2 \%$ in Galle. In Galle, doctors (specialist obstetricians and gynaecologists, medical officers of health and general practitioners) were the leading source of preconception health knowledge, but contributed to preconception health knowledge in only $18.8 \%$ of the total study population of 250 women. The PHM was an important source of preconception health knowledge both in Colombo and in Galle. Since the PHM was responsible for providing preconception health knowledge and PCC for approximately $62 \%$ of the 68 women who received PCC in Galle, greater efforts are needed to improve the capacity of the PHM to provide these services. The PHM should be well-trained to provide information and counseling for women, men, families and community on essential sexual and reproductive health. The target for 2016 is to have $>80 \%$ of Medical Officer of Health (MOH) areas implementing the PCC package designed for Sri Lanka and $>80 \%$ of PHM trained in the delivery of this PCC package ${ }^{13}$.

\section{Conclusion}

PCC for women is an important aspect in primary health care but appears to be suboptimal in Southern Sri Lanka. Electronic and print media may not have a great impact on providing preconception health knowledge unless the socio-economic and educational status improves in the region. Since the focus should be on the younger women, details regarding sexual and reproductive health and PCC could be included in to the curricula of schools and higher educational institutions respectively. Medical Officers of Health, Public Health Midwives and Nurses as well as General Practitioners should be motivated and trained to provide preconception health education and PCC to women in Southern Sri Lanka. Specialist Obstetricians too should focus their attention to this aspect of care.

\section{Acknowledgement}

We thank Dr. C J Wijesinghe, Dr. R M Ruparatne and Dr. S P Mohotti for their invaluable assistance to carry out this study.

\section{REFERENCES}

1. Jack BW, Culpepper L. Preconception care: risk reduction and health promotion in preparation for pregnancy. Journal of American Medical Association 1990; 264: 1147-9.

2. Centers for Disease Control and Prevention. Recommendations to improve preconception health and health care - United States. A report of the CDC/ATSDR Preconception Care Workgroup and the Select Panel on Preconception Care. Morbidity and Mortality Weekly Reports 2006; 55: 1-23.

3. Fowler JR, Jack BS. Preconception care. In: Taylor RB, David AK, Fields SA et al, eds. Family medicine principles and practice, Ed 6, New York: Springer, 2003, 85-94.

4. Henshaw SK. Unintended pregnancy in the United States. Family Planning Perspectives 1998; 30: 24-32.

5. Department of Census and Statistics (DCS) and Ministry of Healthcare and Nutrition $(\mathrm{MOH})$. Sri Lanka Demographic and Health Survey 2006 - 2007, Colombo, Sri Lanka 2009, DCS and MOH.
6. Shah PS, Balkhair T, Ohlsson A, Beyene $J$, Scott F, Frick C. Intention to become pregnant and low birth weight and preterm birth: a systematic review. Maternal and Child Health Journal. 2011; 15: 205-216.

7. Godfrey K. The 'developmental origins' hypothesis: epidemiology. In: Gluckman PD, Hanson M, editors. Developmental origins of health and disease. Cambridge University Press, Cambridge: 2006, p 6-32.

8. Posner SF, Johnson K, Parker C, Atrash $\mathrm{H}$, Biermann. The National Summit on Preconception Care: A Summary of Concepts and Recommendations. Maternal and Child Health Journal. 2006; 10: 199-207.

9. Lumley J, Watson L, Watson M, Bower C. Periconceptional supplementation with folate and /or multivitamins for preventing neural tube defects. Cochrane Database of Systematic Reviews 2007, Issue 4. Art. No.: CD001056. DOI: 10.1002/14651858. CD001056.

10. Talaulikar VS, Arulkumaran S. Folic acid in obstetric practice: A Review. Obstetrical and Gynaecological Survey 2011; 66: 240-7.

11. Sabina de Weerd, Chris M. G. Thomas, Rolf J. L. M. Cikot, Re'gine P. M. SteegersTheunissen, Theo M. de Boo, Eric A. P. Steegers. Preconception Counseling Improves Folate Status of Women Planning Pregnancy. Obstetrical and Gynaecological Survey 2002; 99: 45-50.

12. Young-in Kim. Will mandatory folic acid fortification prevent or promote cancer? American Journal of Clinical Nutrition 2004; 80: 1123-8.

13. Family Health Bureau, Ministry of Healthcare and Nutrition Sri Lanka. Strategic Plan on Maternal and Newborn Health 2016 , Ministry of Healthcare and Nutrition Sri Lanka 2011: p 31 -32 and p 59.

14. Robertson SC, Cutts FT, Samuel R, Diaz-Ortaga JL. Control of Rubella and congenital Rubella syndrome (CRS) in developing countries, Part II: vaccination against Rubella. Bulletin of the World Health Organization 1997; 75(1): 69-80.

15. Wickramasinghe VP, Prageeth PPC, Pulleperuma DS, Pushpakumara KS. Preconceptional care of women at booking visit at De Soysa Maternity Hospital and Castle Street Hospital for Women. Ceylon Medical Journal 2003; 48: 77-9.

16. Warusawithana, CS, Randeniya C. Prepregnancy counselling: the gateway to a 
healthy pregnancy. Sri Lanka Journal of Obstetrics and Gynaecology. 2007; 29: 29-32.

17. World Health Organization and Ministry of Healthcare and Nutrition Sri Lanka. Report of the external review of maternal and newborn health Sri Lanka. World Health Organization Colombo Sri Lanka, 2007: p13.

18. Goonewardene IMR, RPK Deeyagaha Waduge. Adverse effects of teenage preg- nancy. Ceylon Medical Journal 2005; 50: 116120.

19. Fernando N, Perera B, Fernando N, Goonewardene M, Ostbye Truls. Factors associated with sexual behavior among Sri Lankan adolscents. Galle Medical Journal 2009; 14(1): 39-44

20. Perera B, Fonseka PHG. Sexual behavior of Advanced Level Students in Southern Sri Lanka. Journal of the College of Community Physicians in Sri Lanka 1998; 3: 13-17.
21. Ahluwalia IB, Daniel KL. Are women with recent live births aware of the benefits of folic acid? Morbidity and Mortality Weekly Reports 2001; 50: 3-14.

22. Lumbiganon $P$, Laopaiboon $M$, Gulmezoglu M, Zousa JP, Taneepa Nichskul S, Ruyan P et al. Method of delivery and pregnancy outcomes in Asia: The WHO Global Survey on maternal and perinatal health 2007-2008. Lancet 2010; 375: 490-9. 